Article

\title{
Investigation on the Tip Positioning Accuracy of Cable-Driven Serpentine Manipulators
}

\author{
Chutan Lin ${ }^{\dagger}$, Wenjing Zhang ${ }^{\dagger}$ and Han Yuan * \\ School of Mechanical Engineering and Automation, Harbin Institute of Technology (Shenzhen), \\ Shenzhen 518055, China; 19s053045@stu.hit.edu.cn (C.L.); 18S053156@stu.hit.edu.cn (W.Z.) \\ * Correspondence: yuanhan@hit.edu.cn; Tel.: +86-755-8692-1606 \\ + Authors with equal contribution.
}

Received: 10 September 2020; Accepted: 5 October 2020; Published: 9 October 2020

\begin{abstract}
Cable-driven serpentine manipulators (CDSMs), having strong compliance and flexibility, are suitable for flexible operation in confined workspace. Like many other manipulators, it is an important issue to sense the tip pose of CDSMs. In much previous research, the manipulator's tip pose is usually determined by the driving cable lengths. However, little literature has talked about the tip positioning accuracy. This paper focused on this issue, and investigated the effect of the cable hole location error and cable length error on the tip positioning accuracy of CDSMs. For this aim, we firstly established the kinematic model, and then analyzed the influence factors of the tip positioning accuracy. Simulation results show that the cable hole location error and cable length error have significant effects on the tip positioning accuracy, and especially in certain configurations, it can cause an approximate $30 \mathrm{~mm}$ deviation in position. Therefore, in order to improve the tip positioning accuracy of CDSMs, it is necessary to compensate for the cable hole location error and cable length error in the modeling.
\end{abstract}

Keywords: kinematics; accuracy analysis; cable-driven serpentine manipulators

\section{Introduction}

Cable-driven serpentine manipulators (CDSMs) use cables to drive joints' motion to produce the bending and stretching motions. CDSMs have many advantages: They can actively adapt to the changes of the external environment because of the hyper-redundant degree of freedom (DOF); they have high maintainability because of using a reconfigurable module; they can access places that are untouchable to humans; for example, their entire structure can be sealed so that they can operate in harsh environments [1-3]. However, CDSMs also have their own shortcomings: They are more difficult to control due to the hyper-redundant; cables as driving devices reduce their stiffness; their accuracy is relatively lower than the rigid joint-link manipulators.

CDSMs are different from traditional manipulators. The traditional serial manipulator puts the driving device at the motion joint. However, the driving device of the CDSM is installed on the base, which reduces the mass and inertia of manipulator. Consequently, the CDSM can improve the responsiveness and load capacity of manipulator. The CDSM has the advantages on variable configuration, higher load-bearing ratio, and larger task space. However, due to the flexibility of the cable, especially when the manipulator is too long, the tip positioning accuracy of the manipulator's end will be affected severely.

At present, research on CDSMs has mainly focused on mechanism design, kinematic modeling, dynamic modeling, control system, and trajectory planning [4-6]. Choset et al. [7] described the current status of serpentine robot design and path planning underway in their research group and pointed towards future directions of research. Tang et al. [8] presented a method to simplify the motion planning 
process and demonstrated the effectiveness of the presented method by simulations and experiments on a 25 DOFs cable-driven snake robot prototype. Racioppo et al. [9] presented the modeling and control of a planar snake robot composed of modular, single DOF bending units, and optimized key control and design parameters to produce curvature profiles that maximize the robot's forward speed. Qi et al. [10] studied the mapping relationship among the driven space, joint space, and task space of a cable-driven continuum robot and analyzed the decoupling algorithm based on piecewise constant curvature assumption. Yuan et al. analyze the workspace of cable-driven continuum robots [11], and proposed a comprehensive static model for cable-driven continuum robots [12]. Rone et al. [13] studied a novel dynamic modeling methodology that captures curvature variations along a segment using a finite set of kinematic variables and this dynamic model is implemented using the principle of virtual power for a continuum robot. Li et al. [14] designed and built a wire-driven serpentine robot arm which is made of a number of rigid nodes connected by two sets of wires. Wu et al. [15] proposed a real-time position compensation control method based on flexible cable deformation. Qian et al. [16] studied a cable-driven parallel robot for 3D printing to obtain a larger workspace rather than traditional 3D printing devices. Zi et al. [17] conceptualized and designed a waist rehabilitation robot driven by cables and pneumatic artificial muscles (PAMs). Fortin-Côté et al. [18] proposed using cable angle position sensors in addition to cable length measurements in order to improve the accuracy of a cable-driven parallel mechanism (CDPM). Lv et al. [19] studied the sliding mode control of the cable-driven redundancy parallel robot with six degrees of freedom based on the cable-length sensor feedback. Sandretto et al. [20] developed a calibration method for a particular parallel cable-driven robot using a camera for 3D pose sensing. Sareh et al. [21] introduced a pose-sensing system for soft robot arms integrating a set of macrobend stretch sensors. Dallej et al. [22] proposed a 3D pose visual servoing, which was then illustrated and validated on a cable-driven parallel robot prototype.

Although previous research has been done to study the position accuracy problem of cable-driven manipulators, there are few studies which analyze the influence factors that affect the tip positioning accuracy of the CDSM. In this paper, we will establish the kinematic model of CDSMs and analyze the influence of the cable hole location error and cable length error, in order to improve the tip positioning accuracy of the manipulators.

The rest of this paper is organized as follows: In Section 2, the structure sketch of the $n$-DOF planar CDSM is presented. We firstly derive the kinematics model, and then analyze the influence factors of the tip positioning accuracy and propose a corresponding study method. In Section 3, simulation analysis is made on the influence factors that affect the tip positioning accuracy. Then, we make a demonstrative experiment using a CDSM prototype with 3 sections and 6 driving cables to verify the simulation. In Section 4, we make a conclusion about our work and introduce the future plans.

\section{Kinematic Model and Position Accuracy Analysis}

\subsection{The n-DOF Planar CDSM}

The CDSM is usually a hyper-redundant DOF system; its DOF in the joint space is more than that in the task space. For forward kinematics, a set of joint angles corresponds to an end pose. However, the redundant character leads to multiple solutions in inverse kinematics.

In this paper, we studied a CDSM with parallel joints, whose spin axes of the joints were parallel to each other. It could realize planar motion with the movement along $X$ and $Y$ axes and the rotation around the $\mathrm{Z}$ axis.

The structure sketch of the $n$-DOF planar CDSM driven by $m$ cables is shown in Figure 1: Where the colorful thick lines represent rigid links; the red small circles represent joints; the colorful thin lines represent the driving cables; and the ellipses represent supporting disks, on which holes distribute to guide the driving cables. As seen from Figure 1, the manipulator could be divided into a fixed link and $n$ movable links, and these links were connected by $n$ joints. Moreover, each movable link was fixed with a disk, and each disk was controlled by two driving cables to produce a rotational motion. 


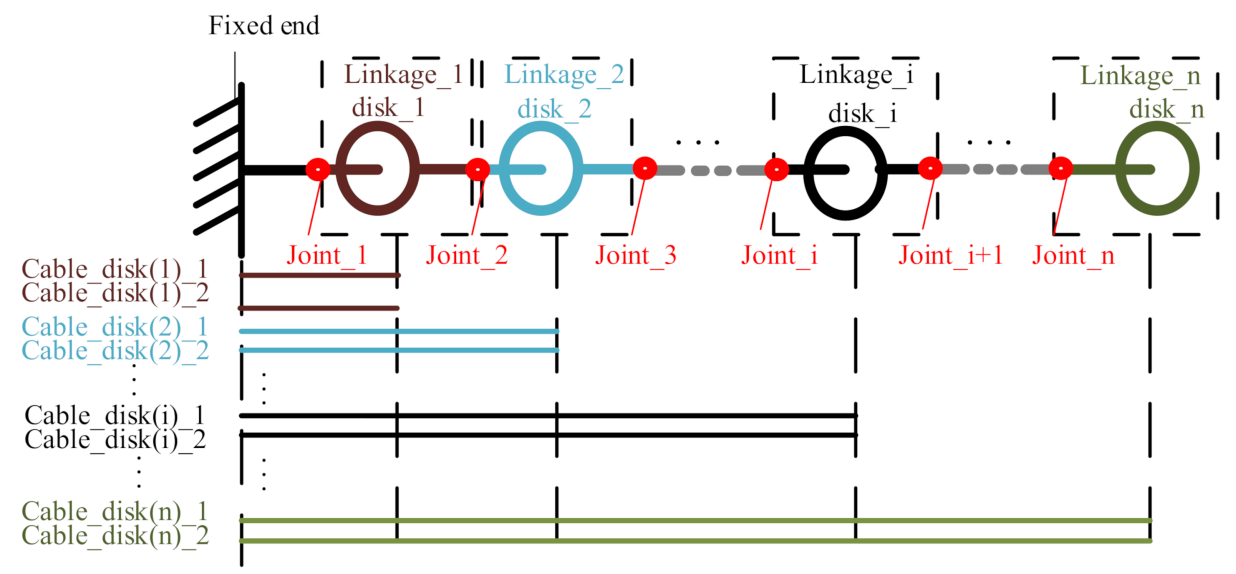

Figure 1. The degree of freedom ( $n$-DOF) planar cable-driven serpentine manipulator (CDSM) (driven by $m$ cables, $m=2 n)$.

To further describe modular unit, the relationship regarding the three adjacent units of the CDSM are presented in Figure 2. As shown in the picture, for the $i^{\text {th }}$ linkage (i.e., linkage_i), it is composed of two links (link $J_{-} i, i$ and $\operatorname{link}_{i, J \_i+1}$ ) and one disk (disk_i) with the thickness of B. $\operatorname{Link}_{i-1, J_{-} i}$ and $\operatorname{link}_{J \_i, i}$ are connected by the $i^{\text {th }}$ joint (i.e., joint_i); similarly, $\operatorname{link}_{i, J \_i+1}$ and $\operatorname{link}_{J \_i+1, i+1}$ are connected by the $(i+1)^{\text {th }}$ joint (i.e., joint_i +1$)$. The cables pass through the holes in the disks to pull the disks, making the joints rotate. For the sake of describing geometric relationship, we set frames on joints and disks: $R_{J_{-}}\left\{O_{J_{-}}, x_{J_{-} i}, y_{J_{-}} i\right\}$ and $R_{J_{-} i+1}\left\{O_{J_{-} i+1}, x_{J_{-} i+1}, y_{J_{-} i+1}\right\}$, respectively, represent the frames on the joint_i and joint_i $+1 ; R_{i, \mathrm{a}}\left\{O_{i, \mathrm{a}}, x_{i, \mathrm{a}}, y_{i, \mathrm{a}}\right\}$ and $R_{i, \mathrm{~b}}\left\{O_{i, \mathrm{~b}}, x_{i, \mathrm{~b}}, y_{i, \mathrm{~b}}\right\}$, respectively, represent the frames on the two sides of the disk_i; $R_{i-1, \mathrm{~b}}\left\{O_{i-1, \mathrm{~b}}, x_{i-1, \mathrm{~b}}, y_{i-1, \mathrm{~b}}\right\}$ and $R_{i+1, \mathrm{a}}\left\{O_{i+1, \mathrm{a}}, x_{i+1, \mathrm{a}}, y_{i+1, \mathrm{a}}\right\}$, respectively, represent the frames on the disk_i -1 the disk_i +1 .

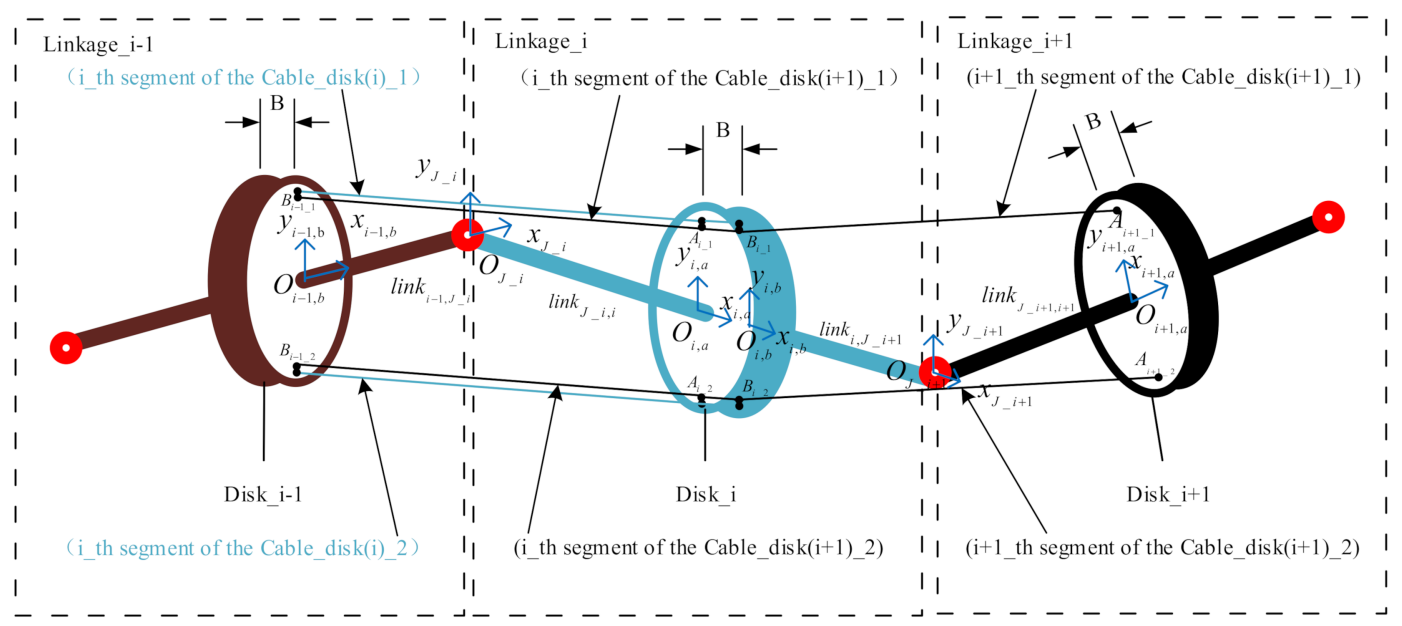

Figure 2. Kinematic relationships of adjacent units of the CDSM.

\subsection{Kinematic Modeling}

\subsubsection{The Mapping between the End Pose and the Joint Angle}

For the $n$-DOF CDSM that can realize planar 3-DOF motion, there is a certain mapping relationship between the joint and the end pose. According to the frames in Figure 2, the homogeneous 
transformation matrix from the frame $R_{i, \mathrm{a}}\left\{O_{i, \mathrm{a}}, x_{i, \mathrm{a}}, y_{i, \mathrm{a}}\right\}$ to the frame $R_{i-1, \mathrm{~b}}\left\{O_{i-1, \mathrm{~b}}, x_{i-1, \mathrm{~b}}, y_{i-1, \mathrm{~b}}\right\}$ can be written as:

$$
\mathrm{O}_{i-1, \mathrm{~b}} \mathbf{T}_{o_{i, \mathrm{a}}}=\left[\begin{array}{ccc}
\cos \theta_{i} & -\sin \theta_{i} & \operatorname{link}_{i-1, \mathrm{~J} \_i}+\operatorname{link}_{\mathrm{J}_{i}, i,} \cdot \cos \theta_{i} \\
\sin \theta_{i} & \cos \theta_{i} & \operatorname{link}_{\mathrm{J}_{\_} i, i} \cdot \sin \theta_{i} \\
0 & 0 & 1
\end{array}\right],
$$

where $\theta_{i}$ represents the rotation angle of the $i^{\text {th }}$ joint, and $\operatorname{link}_{i-1, J_{-} i}$ and $\operatorname{link}_{J_{-} i, i}$ represent connecting rods before and after the $i^{\text {th }}$ joint.

The homogeneous transformation matrix from the frame $R_{i, b}\left\{O_{i, b}, x_{i, b}, y_{i, b}\right\}$ to the frame $R_{i, \mathrm{a}}\left\{O_{i, \mathrm{a}}, x_{i, \mathrm{a}}, y_{i, \mathrm{a}}\right\}$ is:

$$
O_{i, \mathrm{a}} \mathbf{T}_{o_{i, \mathrm{~b}}}=\left[\begin{array}{ccc}
1 & 0 & \mathrm{~B} \\
0 & 1 & 0 \\
0 & 0 & 1
\end{array}\right],
$$

where B represents the thickness of the disks.

Thus, when the joint angles are given, the pose vector of end-effector can be obtained by:

$$
\mathbf{S}=\prod_{i=1}^{n}\left({ }^{O_{i-1, \mathrm{~b}}} \mathbf{T}_{o_{i, \mathrm{a}}} \cdot{ }^{O_{i, \mathrm{a}}} \mathbf{T}_{o_{i, \mathrm{~b}}}\right)\left[\begin{array}{l}
0 \\
0 \\
1
\end{array}\right]
$$

where $i=1, \ldots, n . \boldsymbol{\theta}=\left[\begin{array}{llllll}\theta_{1} & \theta_{2} & \ldots & \theta_{i} & \ldots & \theta_{n}\end{array}\right]^{\mathrm{T}}$ and $\mathbf{S}=\left[\begin{array}{l}X Y \phi\end{array}\right]^{\mathrm{T}}$, respectively, represent the joint angle vector of joints and the pose vector of end-effector.

It should be noticed that we could obtain a unique end pose when the joint angles were determined. However, given the pose vector of the end-effector, multiple vectors of the joint angles could be worked out. This was the multiplicity of inverse kinematics due to the redundancy of the manipulator.

\subsubsection{The Mapping between the Cable Length and the Joint Angle}

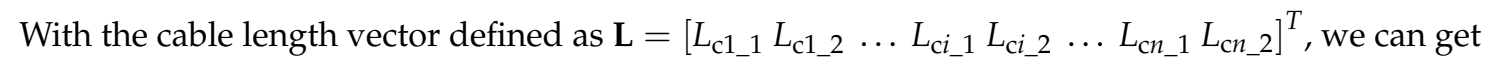
the mapping relationship between the cable length and the end pose when joint angles are given.

$$
\begin{aligned}
& L_{c i \_1}=\sum_{k=1}^{i}\left(\left\|\mathrm{~B}_{i-1 \_1} \mathrm{~A}_{i \_1}\right\|+\mathrm{B}\right), \\
& L_{c i \_2}=\sum_{k=1}^{i}\left(\left\|\mathrm{~B}_{i-1 \_2} \mathrm{~A}_{i \_2}\right\|+\mathrm{B}\right),
\end{aligned}
$$

where, $L_{c i \_1}$ represents the length of the cable_disk(i)_1; $B_{i-1 \_1} A_{i \_1}$ represents the length between disk_i-1 and disk_i of the cable_disk(i)_1 (i.e., the distance between the hole $\mathrm{B}_{i-1} \_1$ and the hole $\mathrm{A}_{i_{-} 1}$, shown in Figure 2); $L_{c i \_2}$ represents the length of the cable_disk(i)_2; and $\mathrm{B}_{i-1 \_2} \mathrm{~A}_{i_{2} 2}$ represents the length between disk_i-1 and disk_i of the cable_disk(i)_2 (i.e., the distance between the hole $B_{i-1 \_2}$ and the hole $\mathrm{A}_{i_{-} 2}$ ).

Given a joint angle vector of the manipulator, the length of each driving cable can be calculated by Equations (4) and (5). However, the same cable lengths may correspond to different joint angle vectors, that is, the mapping from cable lengths to joint angles was a one-to-many relationship.

\subsection{Influence Factors of Tip Positioning Accuracy}

The control methods of the CDSM included all cables in the position control mode, all cables in the force control mode, and cables in a hybrid control mode (i.e., some cables in the position control mode and others in the force control mode.). When all cables were in the position control mode, the driving cables could be overly tensioned or relaxed. Additionally, with the number of cables increases, it 
was more difficult to control. When all cables were in the force control mode, the control was simple, but it was hard to ensure the tip positioning accuracy. Therefore, we chose a hybrid control mode, which could ensure the tip positioning accuracy and reduce the control difficulty as well. In this paper, for the experiment's convenience, we chose for the upper cables $\left(L_{\mathrm{ci} i}\right)$ to adopt the position control mode, and the force control mode was applied to the lower cables $\left(L_{c i \_} 2\right)$. In fact, each cable could use the position control mode or force control mode.

However, in the practical control process, it was unavoidable to produce control error. For example, between the actual cable length and theoretical cable length existed small difference. In addition, the driving cable passing through the guiding hole on disk may not have been along the center axis of the hole. All these factors affected the tip positioning accuracy of the manipulator.

This paper studied the influence factors of the tip positioning accuracy in CDSMs' workspace; that is, how the cable length error and cable hole location error to affect the end pose. The processes that study the influence of cable length error, the cable hole location error, and the combined error of two on the tip positioning accuracy are illustrated in Figure 3.

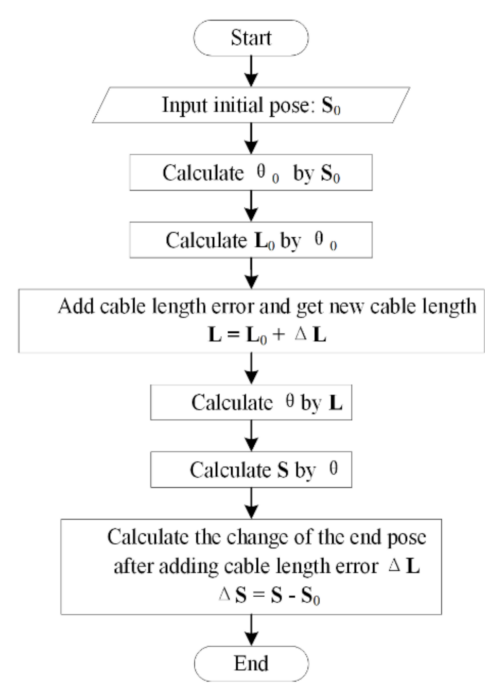

(a)

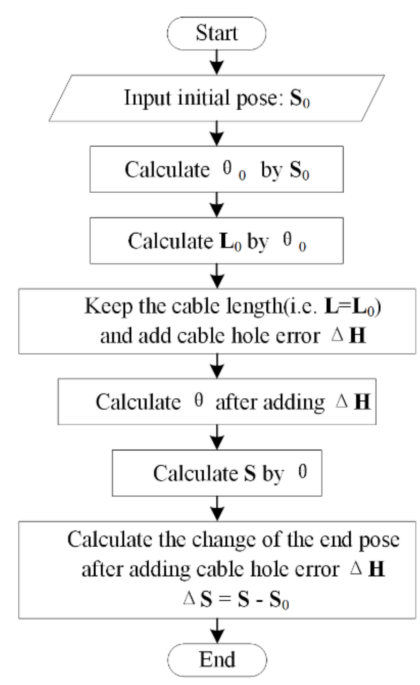

(b)

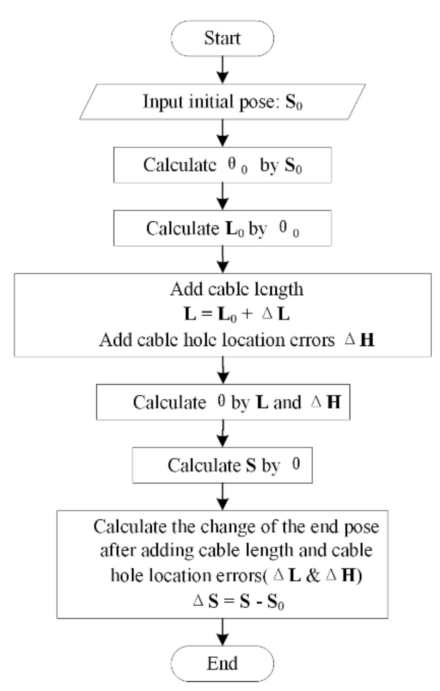

(c)

Figure 3. Flow charts to study the errors. (a) The method to study the cable length error; (b) the method to study the cable hole location error; (c) the method to study the combined cable length and cable hole location errors.

Figure 3a shows the processes that study the influence of the cable length error. Given the initial pose $S_{0}$, we could calculate the initial joint angle $\theta_{0}$ and initial cable length $L_{0}$. Then, we added the cable length error $\Delta \mathrm{L}$ and got the new cable length $\mathrm{L}\left(\mathrm{L}=\mathrm{L}_{0}+\Delta \mathrm{L}\right)$. We could obtain a new joint angle $\theta$ and new pose $S$ by L. $\Delta S$ was the influence of cable length error on the tip positioning accuracy.

Figure $3 b$ shows the processes that study the influence of the cable hole location error. Given the initial pose $S_{0}$, we could calculate the initial joint angle $\theta_{0}$ and initial cable length $L_{0}$. When the cable lengths stayed the same $\left(\mathrm{L}=\mathrm{L}_{0}\right)$, we added the cable hole location error $\Delta \mathrm{H}$ (i.e., changing the location of the holes $\left.\mathrm{A}_{i_{-} 1}, \mathrm{~A}_{i_{-} 2}, \mathrm{~B}_{i_{-} 1}, \mathrm{~B}_{i_{2} 2}\right)$, which influenced the $\mathrm{B}_{i-1} 1_{1} \mathrm{~A}_{i_{-} 1}$ and $\mathrm{B}_{i-1 \_2} \mathrm{~A}_{i_{2} 2}$ shown in Equations (4) and (5). Then we could obtain a new joint angle $\theta$ and new pose $S$ by $L$ and $\Delta H . \Delta S$ was the influence of the cable hole location error on the tip positioning accuracy.

Figure $3 c$ shows the processes that study the influence of the combined error of cable length and hole location. Given the initial pose $S_{0}$, we could calculate the initial joint angle $\theta_{0}$ and initial cable length $\mathrm{L}_{0}$. Then, we added the cable length error $\Delta \mathrm{L}$ and got a new cable length $\mathrm{L}\left(\mathrm{L}=\mathrm{L}_{0}+\Delta \mathrm{L}\right)$. At the same time, we added the cable hole location error $\Delta \mathrm{H}$ to change the $\mathrm{B}_{i-1 \_1} \mathrm{~A}_{i_{-} 1}$ and $\mathrm{B}_{i-1 \_2} \mathrm{~A}_{i_{-} 2}$. Then we 
could obtain the new joint angle $\theta$ and new pose $S$ by $L$ and $\Delta H . \Delta S$ was the influence of the combined error of two on the tip positioning accuracy.

It should be noted that $\mathrm{L}$ in Figure $3 \mathrm{~b}$ is $\mathrm{L}=\mathrm{L}_{0}$, because when we only studied the cable hole location error, the cable length could not change. However, $\mathrm{L}$ in Figure $3 \mathrm{c}$ is $\mathrm{L}=\mathrm{L}_{0}+\Delta \mathrm{L}$, because when we considered the combined error, we needed to change the cable length as well as the cable hole location.

\section{Simulation Analysis and Experimental Validation}

This section is divided by subheadings. It should provide a concise and precise description of the experimental results, their interpretation, as well as the experimental conclusions that can be drawn.

\subsection{Parameters Setting}

Simulations were performed by taking a 3-DOF planar CDSM as an example. This manipulator had 3 joints and 6 cables (i.e., $n=3, m=6$ ), which could realize three the degrees of freedom of movement in the plane. Its structure sketch is shown in Figure 4. There were a total of six cables and three disks in the experimental device. Each disk was controlled by two cables. The first, third, and fifth cables, corresponding to the upper cables of disk_1, disk_2, and disk_3, are cable_disk(1)_1, cable_disk(2)_1, and cable_disk(3)_1 in Figure 4, respectively.

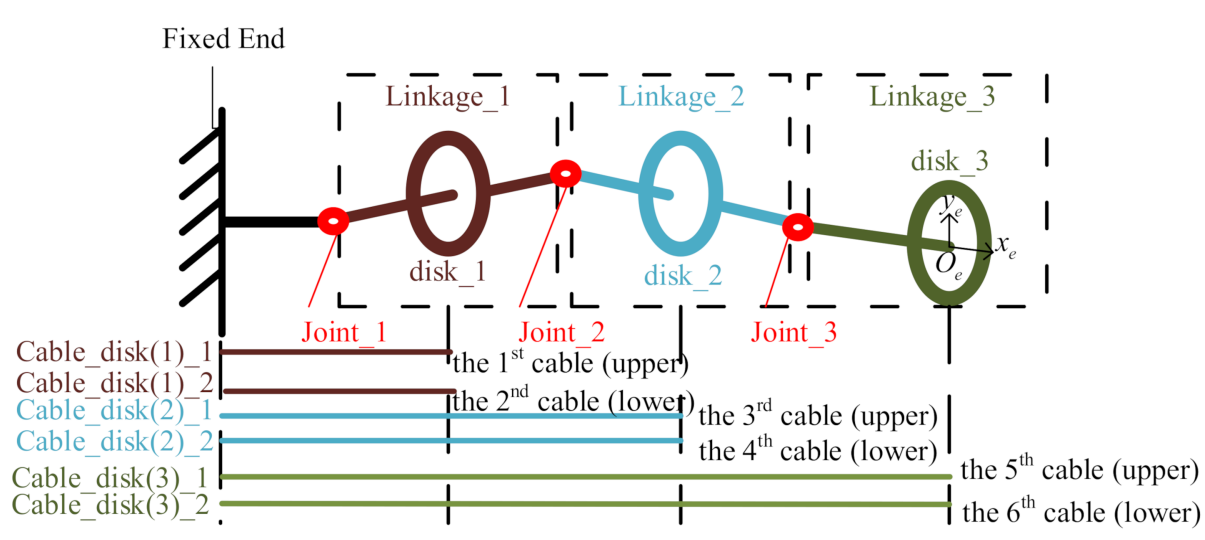

Figure 4. 3-DOF planar CDSM (driven by 6 cables).

The structure parameters of the manipulator are shown in Table 1. The height of the hole represented the distance between the center of hole and the geometric center of disk. As shown in Figure 2, the height of the hole in disk_i was the distance between $O_{i, \mathrm{a}}$ and $A_{i \_1}$, which was the same as the distance from $O_{i, \mathrm{a}}$ and $A_{i \_2}$. In Table $1,0.030 \mathrm{~m}$ is the height of hole in disk $\_1 ; 0.028 \mathrm{~m}$ is the height of hole in disk_2; and $0.026 \mathrm{~m}$ is the height of hole in disk_3.

Table 1. Structure parameters of the 3-DOF planar CDSM.

\begin{tabular}{ccccc}
\hline & \multicolumn{2}{c}{ Dimension Parameter $(\mathbf{m})$} & Mass $(\mathbf{k g})$ & Height of Hole $(\mathbf{m})$ \\
\hline Fixed End & link $_{0, J_{-} 1}$ & 0.033 & & \\
& link $_{J_{-} 1,1}$ & 0.033 & & 0.030 \\
Linkage_1 & $B$ & 0.010 & 0.0322 & \\
& link $_{1, J_{-} 2}$ & 0.033 & & \multirow{2}{*}{0.028} \\
& link $_{J-2,2}$ & 0.033 & & \\
Linkage_2 & $B$ & 0.010 & 0.0334 & 0.026 \\
& link $_{2, J-3}$ & 0.033 & & \\
Linkage_3 & link $_{J-3,3}$ & 0.033 & 0.0210 & \\
& $B$ & 0.010 & & \\
\hline
\end{tabular}




\subsection{Simulation Analysis}

Taking the proposed manipulator model in Section 3.1 as the research object, the factors affecting the tip positioning accuracy of the manipulator were analyzed by adopting the methods proposed in Section 2.3. In order to simplify the analysis, the end-effector attitude of the manipulator was set as zero; that is, the end-effector attitude always kept parallel to the ground. We analyzed the influence of the cable hole location error and cable length error on the tip positioning accuracy in the manipulator's workspace. Due to this, simulations were performed by taking a 3-DOF planar CDSM as an example; that is, there were 3 joints in total. The minimum joint angle was $-30^{\circ}$ and the maximum joint angle was $30^{\circ}$. Every joint moved from $-30^{\circ}$ to $30^{\circ}$ with the step size of $5^{\circ}$. Multiple sets of joint angles were obtained through three nested loops, the corresponding tip positions of those joint angles form the workspace.

Firstly, we analyzed the influence of the cable length error:

- Add $\pm 1 \mathrm{~mm}$ error to the first cable;

- Add $\pm 1 \mathrm{~mm}$ error to the third cable;

- Add $\pm 1 \mathrm{~mm}$ error to the fifth cable,

where adding $+1 \mathrm{~mm}$ error meant that the cable length was lengthened by $1 \mathrm{~mm}$, and adding $-1 \mathrm{~mm}$ error meant that the cable length was shortened by $1 \mathrm{~mm}$.

Next, we analyzed the influence of the cable hole location error:

- Add $\pm 0.35 \mathrm{~mm}$ error to the first disk's holes;

- Add $\pm 0.35 \mathrm{~mm}$ error to the second disk's holes;

- Add $\pm 0.35 \mathrm{~mm}$ error to the third disk's holes,

where adding $+0.35 \mathrm{~mm}$ error meant that the cable hole height was increased by $0.35 \mathrm{~mm}$, and adding $-0.35 \mathrm{~mm}$ error meant that the cable hole height was reduced by $0.35 \mathrm{~mm}$.

Figure 5 shows the results of adding the cable length error. Figure 6 shows the results of adding the cable hole location error. It should be noted that the points in the pictures were obtained by traversal of joint angles; that is, a combination of the joint angles varying from the minimum to the maximum. These points almost covered the entire workspace of the manipulator's tip.
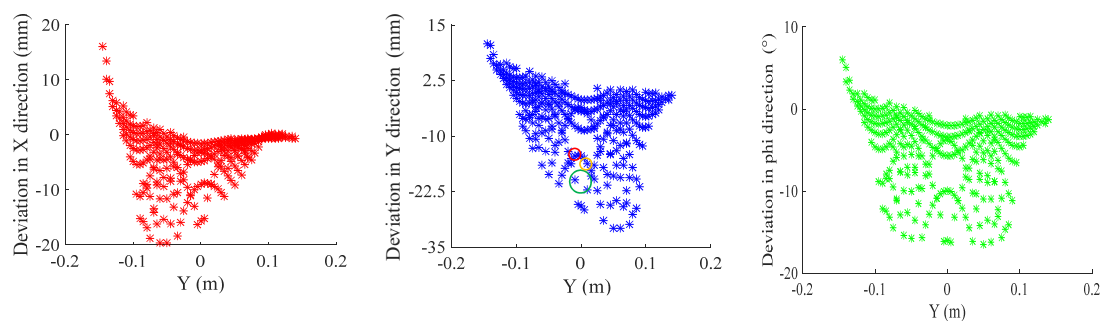

(a)
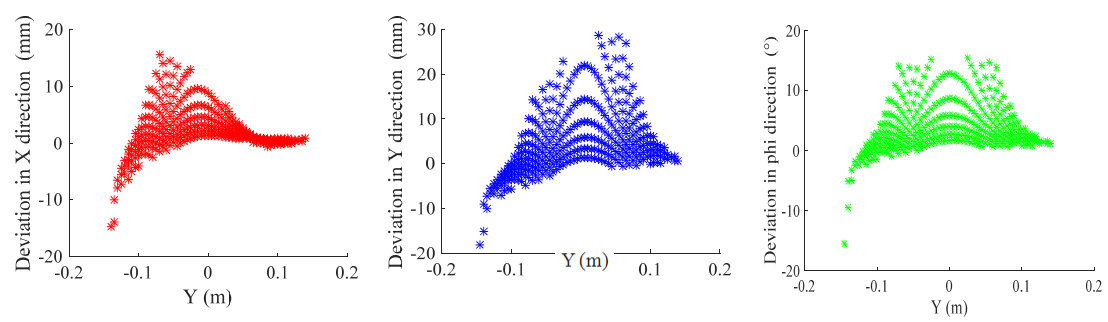

(b)

Figure 5. Cont. 

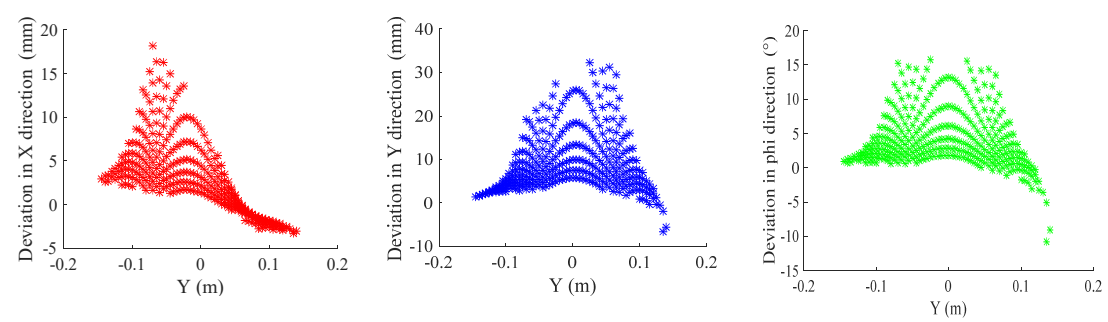

(c)
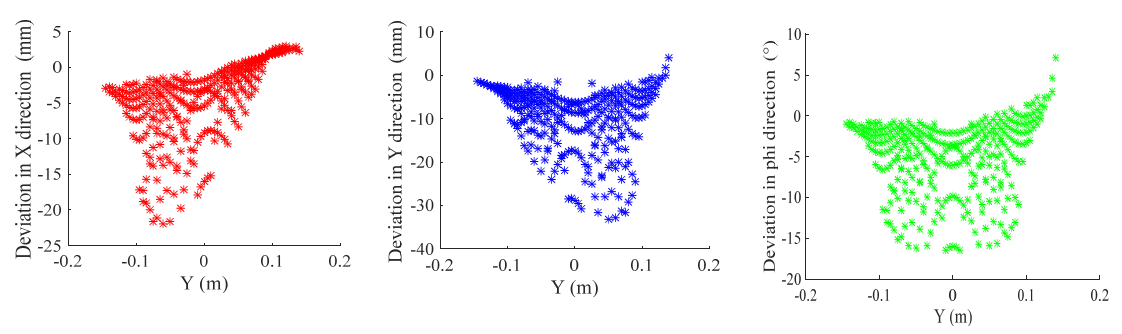

(d)
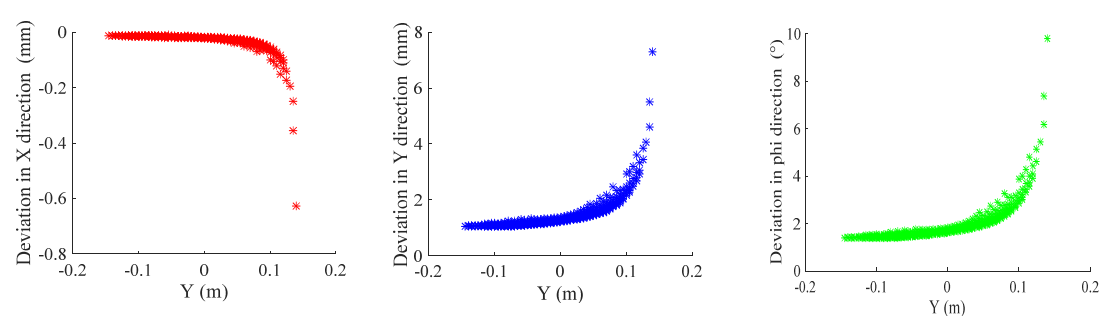

(e)
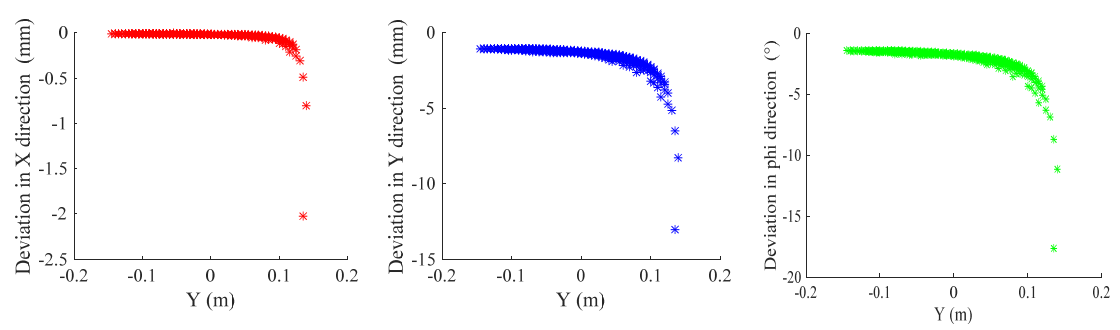

$(\mathbf{f})$

Figure 5. The influence of the cable length error on the tip positioning accuracy: (a) Adding $-1 \mathrm{~mm}$ error to the first cable; (b) adding $+1 \mathrm{~mm}$ error to the first cable; (c) adding $-1 \mathrm{~mm}$ error to the third cable; (d) adding $+1 \mathrm{~mm}$ error to the third cable; (e) adding $-1 \mathrm{~mm}$ error to the fifth cable; (f) adding $+1 \mathrm{~mm}$ error to the fifth cable.
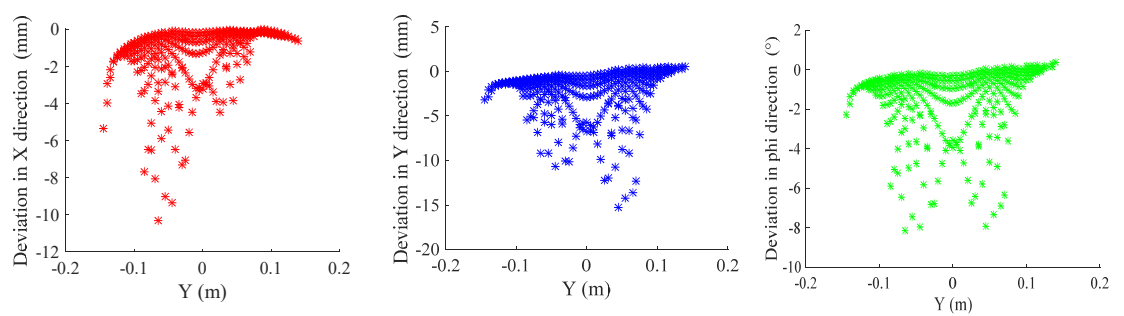

(a)

Figure 6. Cont. 

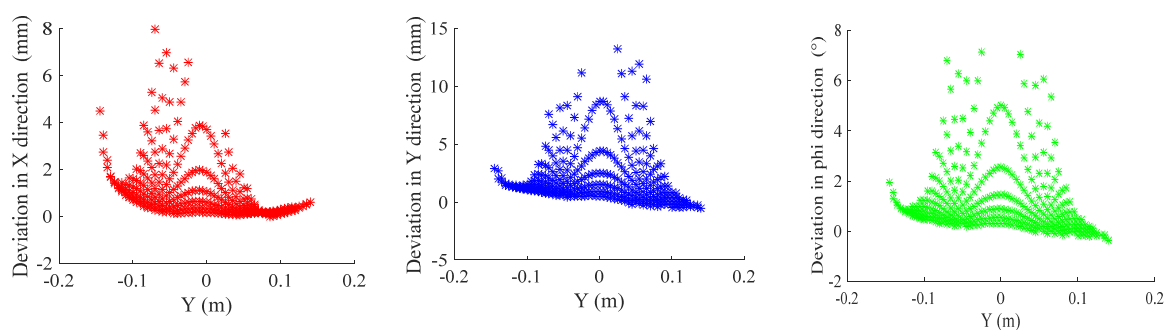

(b)
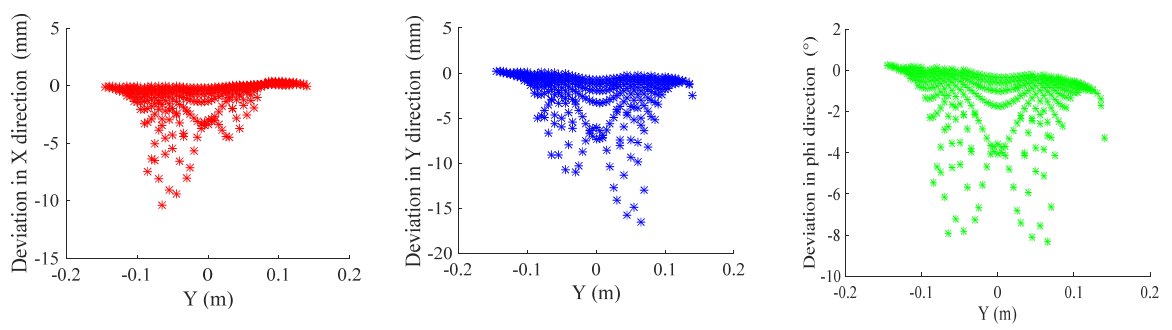

(c)
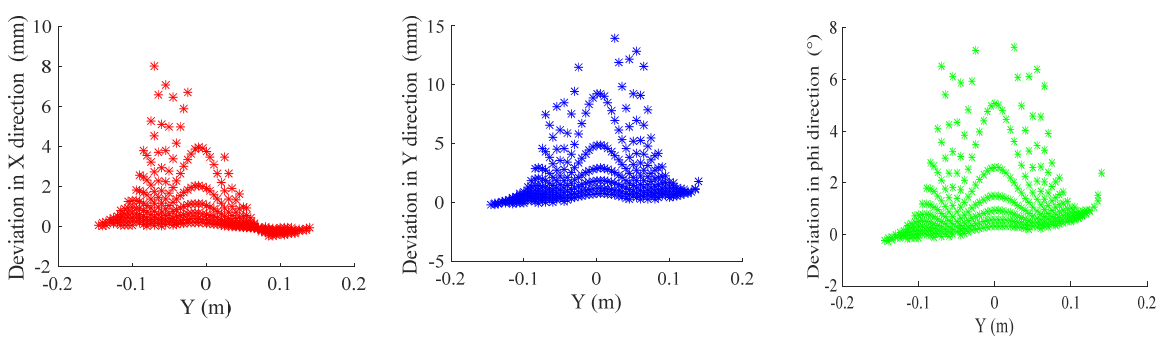

(d)
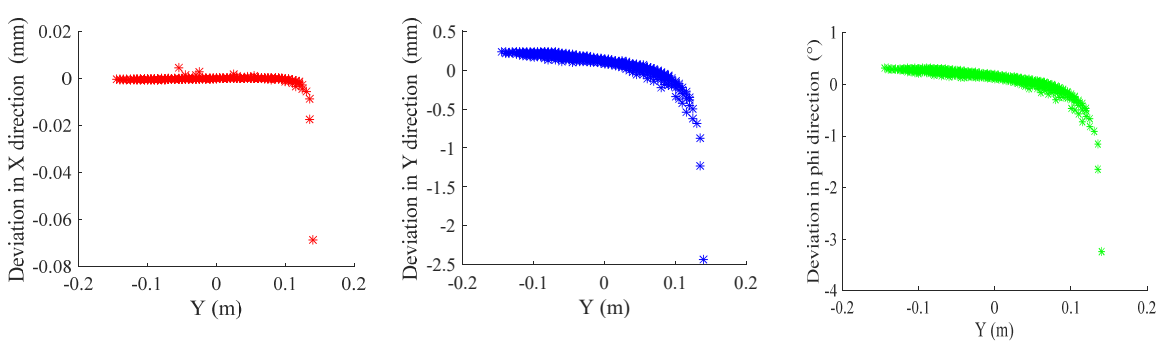

(e)
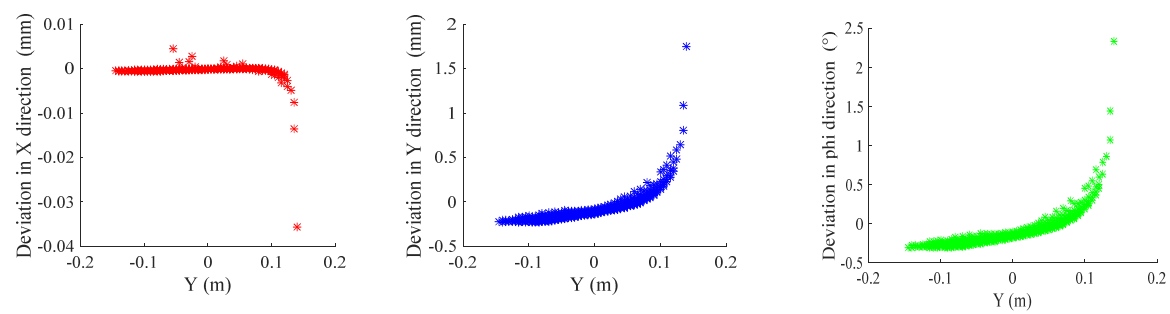

(f)

Figure 6. The influence of the cable hole location error on the tip positioning accuracy: (a) Adding $-0.35 \mathrm{~mm}$ error to the first disk's holes; (b) adding $+0.35 \mathrm{~mm}$ error to the first disk's holes; (c) adding $-0.35 \mathrm{~mm}$ error to the second disk's holes; (d) adding $+0.35 \mathrm{~mm}$ error to the second disk's holes; (e) adding $-0.35 \mathrm{~mm}$ error to the third disk's holes; (f) adding $+0.35 \mathrm{~mm}$ error to the third disk's holes. 
The red color represents the influence of the cable length error on the tip in the $X$ direction; blue color represents the influence on the tip in the $Y$ direction; green color represents the influence on the tip attitude.

From the above 36 figures, the following conclusions can be obtained:

1. When we added $-1 \mathrm{~mm}$ error to the first cable/ $+1 \mathrm{~mm}$ error to the third cable/ $-0.35 \mathrm{~mm}$ error to the first disk's holes/ $-0.35 \mathrm{~mm}$ error to the second disk's holes, it generated jump points (i.e., the variation tendency about deviation of the end pose changed at these points);

2. When we added $+1 \mathrm{~mm}$ error to the first cable/ $-1 \mathrm{~mm}$ error to the third cable/ $+0.35 \mathrm{~mm}$ error to the first disk's holes/ $+0.35 \mathrm{~mm}$ error to the second disk's holes, from both ends of the $Y$-axis to $Y=0$, the deviation of the end pose gradually increased and reached the maximum value nearby $\mathrm{Y}=0$;

3. When we added $\pm 1 \mathrm{~mm}$ error to the fifth cable/ $+0.35 \mathrm{~mm}$ error to the third disk's holes, the maximum deviation of the end pose was at the positive $Y$-axis boundary;

4. The influence of the first and third cable errors and the first and second cable location hole errors was larger than that of the fifth cable error and the third cable location hole error; that is, the closer to the end, the smaller the influence of cable length and cable location hole errors on the end accuracy;

5. The effect of the cable hole location error on the tip positioning accuracy was smaller than that of the cable length error.

To better explain "jump points", we pick the blue picture from Figure $5 \mathrm{a}$; the points in the green circle are defined as jump points because the variation trend of the deviation before and after the points in the green circle changed. At the same time, the deviation suddenly changed greatly from the points in the green circle to the points in the red or yellow circles.

Finally, we analyzed the influence of combining the cable length error with the cable hole location error. We added random cable length errors within the range from -1 to $+1 \mathrm{~mm}$ to each upper cable. At the same time, we added random cable hole location errors within the range from -0.35 to $+0.35 \mathrm{~mm}$ to each disk. A total of 1000 groups of random composite errors were used in the simulation. The average deviation value of 1000 groups of random composite errors were calculated and plotted as seen in Figure 7.

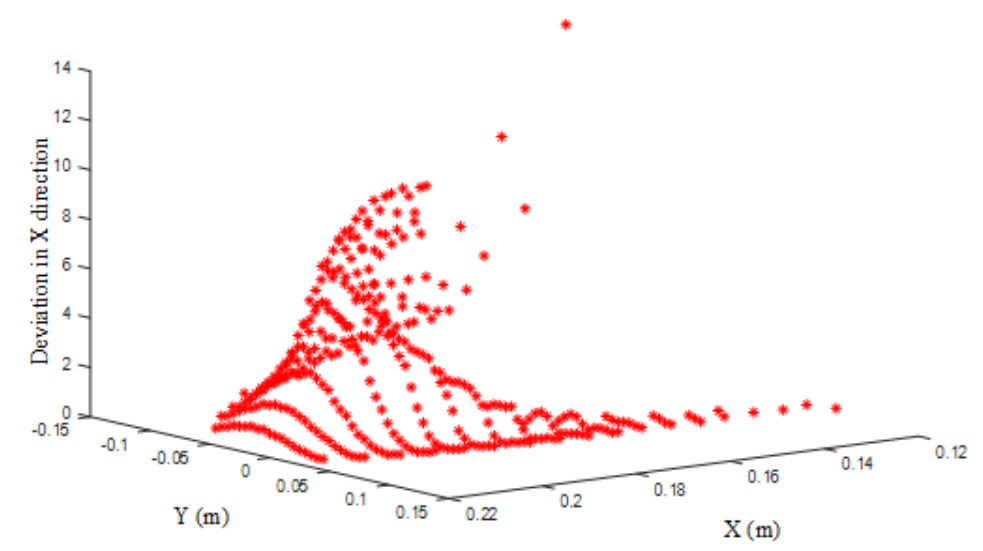

(a)

Figure 7. Cont. 


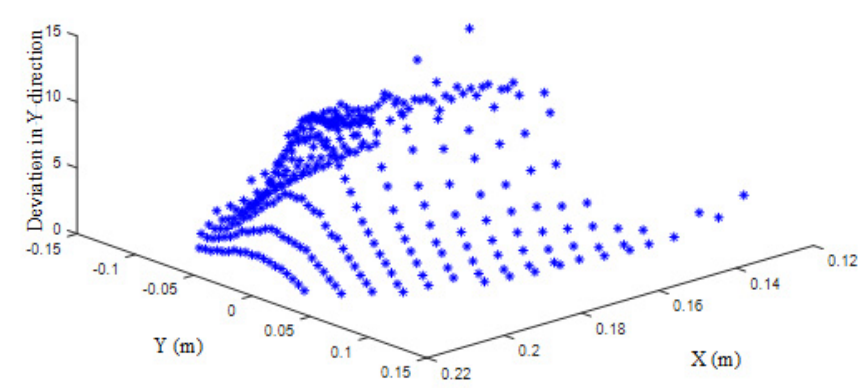

(b)

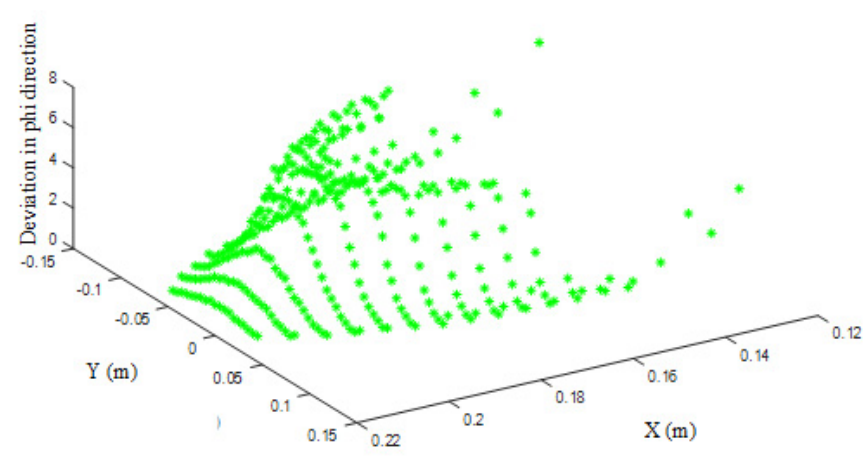

(c)

Figure 7. The influence of the random composite error on the tip positioning accuracy. (a) The influence of the cable length error on the tip in the $X$ direction; $(b)$ the influence of the cable length error on the tip in the $\mathrm{Y}$ direction; (c) the influence of the cable length error on the tip in the phi direction.

In Table 2, the blue line represents the initial state of the manipulator. The red line represents the state after adding errors. As can be seen from the configuration diagram, reducing the error values or avoiding the jump points and some boundary points could improve the tip positioning accuracy effectively.

\subsection{Experimental Validation}

According to the experimental prototype shown in Figure 8, we set the experimental conditions as follows:

- Joint angles: $-35^{\circ} \leq \theta \leq 35^{\circ}$;

- External forces: $0 \mathrm{~N} ; 0 \mathrm{~N} ; 0 \mathrm{Nm}$;

- Lower cable tensions(weights): 50; 10; $5 \mathrm{~g}$;

- Cable length error: $-1 \mathrm{~mm}$.

In order to avoid interference between cables and links, we set variation range of joint angles. It should be noted that the lower cables were in the force control mode, and when the lower cable tensions changed, the upper cable tensions changed; thus, we had to guarantee that cable tensions were all positive. In this simulation example, we added $-1 \mathrm{~mm}$ error to the first cable, because the first cable was shorter than the third and fifth cables. The same cable length error would cause larger deviation on short cable, which was convenient to measure. Too small deviation resulted in inaccurate results due to the measurement and systematic errors. Compared to the cable length, $1 \mathrm{~mm}$ was a reasonable error value. Adding negative error meant that the cable length was shortened, which was convenient in order to adjust the cable length. 
Table 2. Changes of the end pose under different conditions.

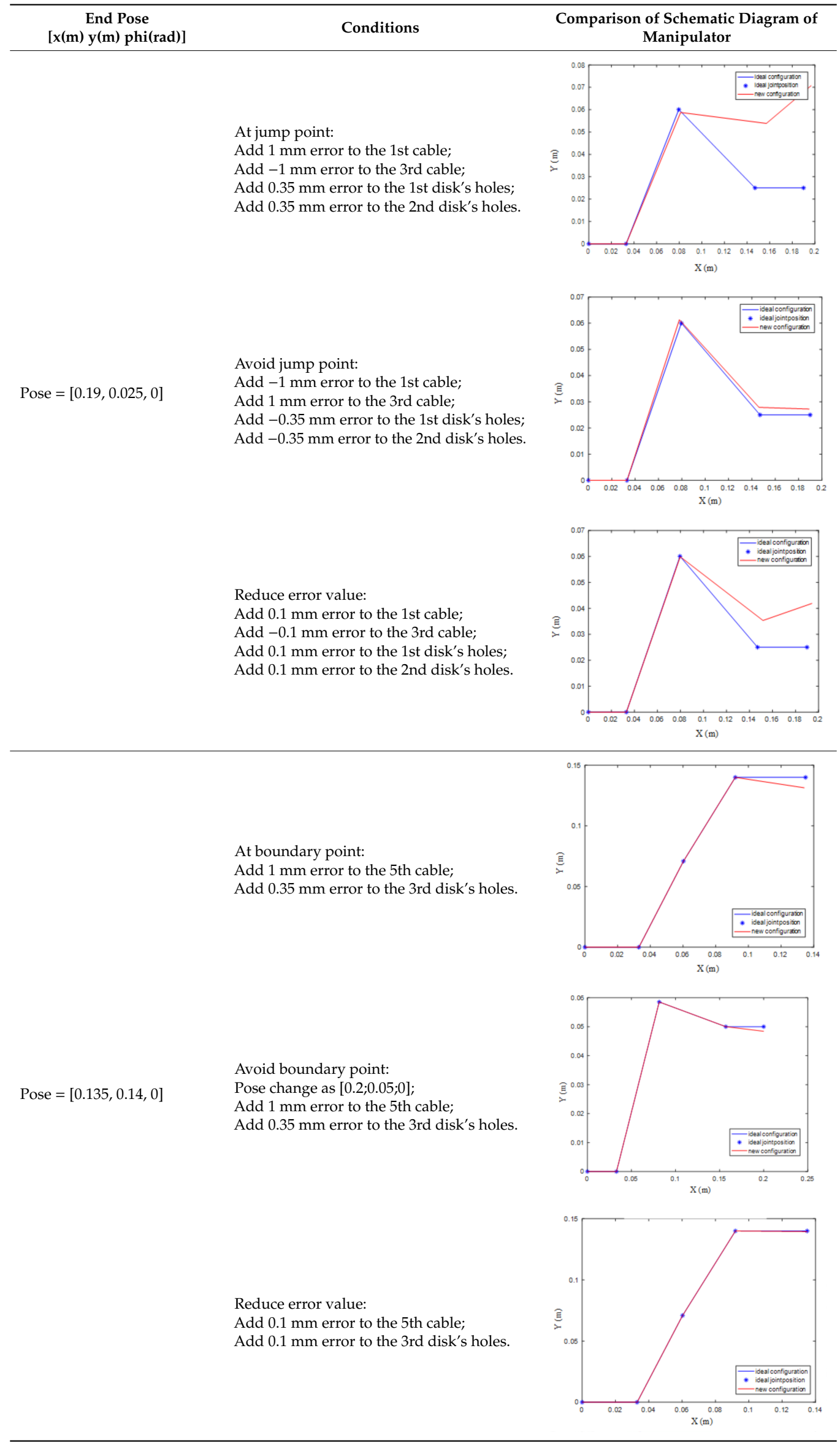




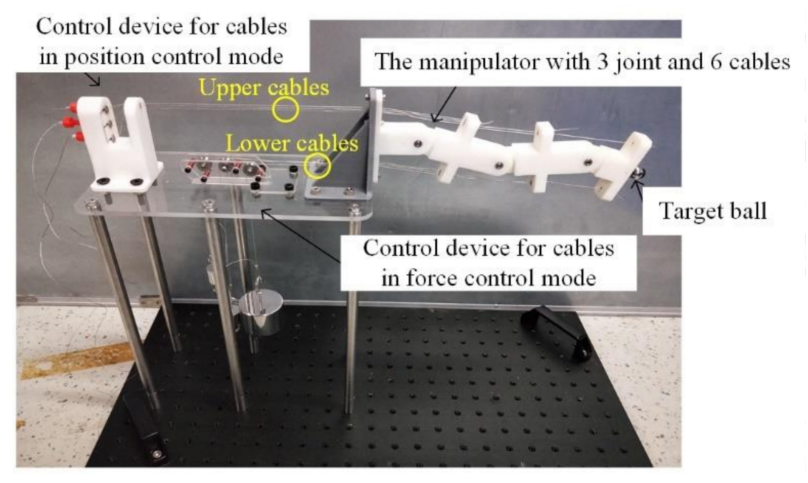

Figure 8. Experimental prototype and overall layout.

As shown in Figure 8, joints were connected by bearing and needle roller. It is noted that the friction in this system was minimized by using bearing, pulley, and lubricating grease. The position control device was composed of a retaining bracket with a screwed hole and three screws; we could adjust the cable length by rotating the screws. The force control device was composed of a pulley block and three standard weights (the standard weights hung on the second, fourth, and sixth cables were 5, 10 , and $50 \mathrm{~g}$, respectively); we could change the cable tension by changing the number of weights.

For the cables in the position control mode, one end of the cable was tied to the disk, and the other end of the cable was driven by the screw, because the cable length was adjusted by rotating the screw. For the cables in the force control mode, one end of the cable was tied to the disk, and the other end of the cable was driven by standard weights, because the cable tension was applied by the weight bypassing the pulley. As shown in Figure 8, if we put the force control cables together (the lower cables), we could make a pulley block to control it, which simplified the prototype design and was convenient to add weights. If we put the position control cables together (the upper cables), we could concentrate the screwed holes on a device to control cable length.

The location of the tip was set at the center of the target ball. A laser tracker (API Radian Plus), tracking the target ball on the tip of manipulator, was used to measure the tip position. Three groups of steel cables $(0.18 \mathrm{~mm}$ in diameter) with tensile structure were used as driving cables. The Young's modulus of steel cables $\left(0.18 \mathrm{~mm}\right.$ in diameter) used in the experiments was approximately $1.8 \times 10^{11} \mathrm{~Pa}$. Under the maximum external force $(50 \mathrm{~g})$, the cable elongation of with length of about $230 \mathrm{~mm}$ used in the experiments was approximately $0.0234 \mathrm{~mm}$. Hence, the cable elongation could be very small and negligible.

Under the above experimental conditions, the motion range of the end was $X=0.19 \sim 0.23 \mathrm{~m}$ and $\mathrm{Y}=-0.1 \sim 0.1 \mathrm{~m}$; the manipulator's workspace is shown in Figure 9. The deviation of the tip position caused by the cable length error seen from the $X$ and $Y$ directions is shown in Figures 10 and 11.

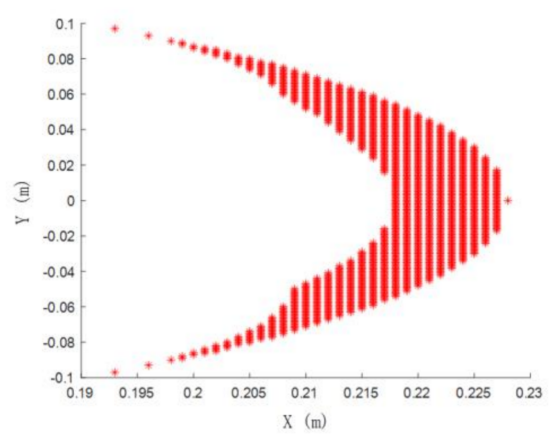

Figure 9. The workspace of experimental prototype. 


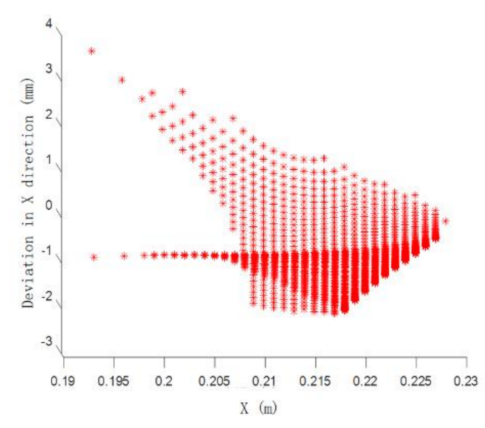

(a)

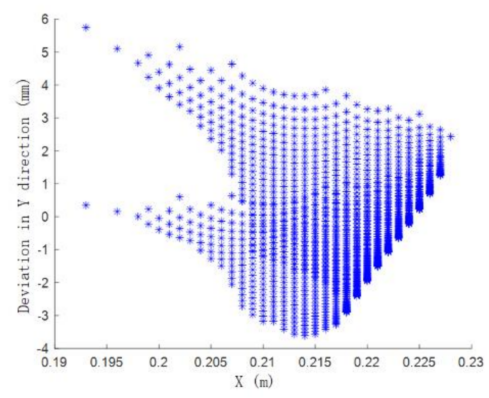

(b)

Figure 10. The deviation of the tip position caused by the cable length error seen from $X$ direction: (a) The deviation in $\mathrm{X}$ direction; (b) the deviation in $\mathrm{Y}$ direction.

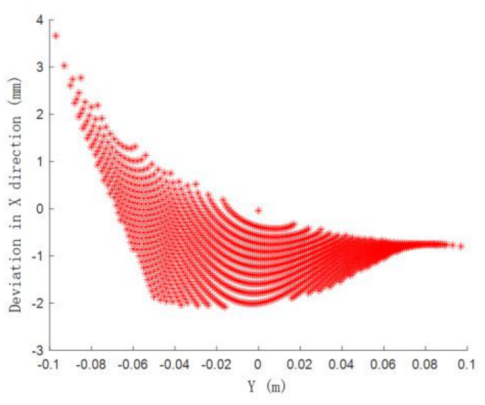

(a)

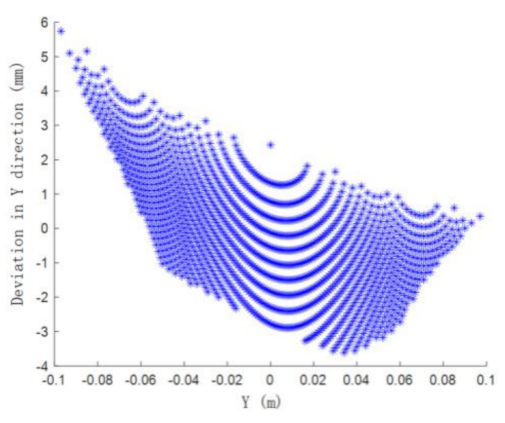

(b)

Figure 11. The deviation of the tip position caused by the cable length error seen from $Y$ direction: (a) The deviation in $\mathrm{X}$ direction; (b) the deviation in $\mathrm{Y}$ direction.

Some points in the workspace were selected for verification experiments. There were 9 groups of experiments, which can be classified into 4 types:

- The point where the manipulator was in a singular state: The first experiment point;

- The jump points: The fourth experimental point, the fifth experimental point, the sixth experimental point;

- The points where the deviation of the tip position was large: The second experiment point, the third experiment point;

- The points where the deviation of the tip position was small: The seventh experimental point, the eighth experimental point, the ninth experimental point.

The comparison between the theoretical deviation value of the tip position caused by the cable length error obtained through simulation and the actual deviation value measured through experiment is listed in Table 3.

Table 3. Comparison of theoretical and actual deviation values.

\begin{tabular}{lllll}
\hline & $\begin{array}{l}\text { Experiment Point } \\
{[\mathbf{X} / \mathbf{m ~ Y / m ~ p h i / r a d}]}\end{array}$ & $\begin{array}{l}\text { Theoretical Deviation } \\
{[\mathrm{X} / \mathbf{m m ~ Y / m m}]}\end{array}$ & $\begin{array}{l}\text { Actual Deviation } \\
{[\mathrm{X} / \mathbf{m m} \mathbf{\text { Y}} / \mathbf{m m}]}\end{array}$ & $\begin{array}{l}\text { Absolute Difference } \\
{[\mathrm{X} / \mathbf{m m} \mathbf{Y} / \mathbf{m m}]}\end{array}$ \\
\hline 1 & {$[0.228,0,0]$} & {$[-0.0415,2.4299]$} & {$[-0.0495,2.2675]$} & {$[-0.0080,-0.1624]$} \\
2 & {$[0.193,-0.097,0]$} & {$[3.6630,5.7446]$} & {$[3.5557,5.3254]$} & {$[-0.1073,-0.4192]$} \\
3 & {$[0.196,-0.093,0]$} & {$[3.0294,5.1021]$} & {$[2.904,4.7657]$} & {$[-0.1254,-0.3364]$} \\
4 & {$[0.202,-0.083,0]$} & {$[1.7697,3.7680]$} & {$[1.8601,3.8436]$} & {$[0.0904,0.0756]$} \\
5 & {$[0.202,-0.084,0]$} & {$[2.1139,4.2225]$} & {$[1.7363,3.5721]$} & {$[-0.3776,-0.6504]$} \\
6 & {$[0.202,-0.085,0]$} & {$[2.7725,5.1599]$} & {$[2.7168,5.0764]$} & {$[-0.0557,-0.0835]$} \\
7 & {$[0.225,-0.008,0]$} & {$[-0.6359,0.6016]$} & {$[-0.5318,0.5521]$} & {$[0.1041,-0.0495]$} \\
8 & {$[0.193,0.097,0]$} & {$[-0.7987,0.3510]$} & {$[-0.7111,0.3552]$} & {$[0.0876,0.0042]$} \\
9 & {$[0.196,0.093,0]$} & {$[-0.7738,0.1592]$} & {$[-0.6763,0.1999]$} & {$[0.0975,0.0407]$} \\
\hline
\end{tabular}


It can be seen from the Table 3 that the experimental results were basically as expected: At the points where the deviation of the tip position was large (such as the second and third experimental points), the tip position produced a deviation of about a few millimeters when the length of the first cable shortened $1 \mathrm{~mm}$; at the points where the deviation of the tip position was small (such as the seventh, eighth, and ninth experimental points), the tip position produced a deviation of about a fraction of a millimeter; at the jump points where the deviation of the tip position suddenly changed (such as the fourth, fifth, and sixth experimental points), the deviation of the tip position at the jump point was nearly doubled compared to the previous point; when the manipulator was in a singular state (all joint angles were zero), the deviation of the tip position in the $\mathrm{X}$ direction was smaller than that in the $Y$ direction.

As shown in Figure 12a, all joint angles were zero, and the tip pose of the manipulator was $0.228 \mathrm{~m}$, $0 \mathrm{~m}$ and $0^{\circ}$. At this point, the manipulator was in a singular state. We added $-1 \mathrm{~mm}$ of cable length error to this singular configuration, and the changes of the pose are shown in Figure 12b. From the results of the simulation and experiment, the theoretical deviations in the simulation of the tip position in the $X$ and $Y$ directions were -0.0415 and $2.4299 \mathrm{~mm}$; the actual deviations in the experiment were -0.0495 and $2.2675 \mathrm{~mm}$. The absolute differences of the simulation and experiment were -0.0080 and $-0.1624 \mathrm{~mm}$; that is, the deviation of the tip position in the $\mathrm{X}$ direction was significantly smaller than that in the $\mathrm{Y}$ direction, because the manipulator lost the freedom of the $\mathrm{X}$ direction in this singular state.

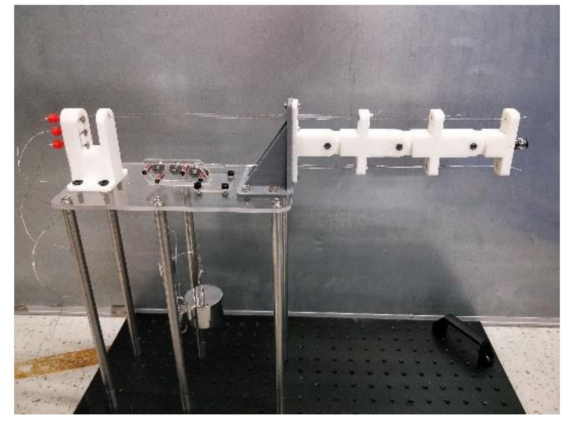

(a)

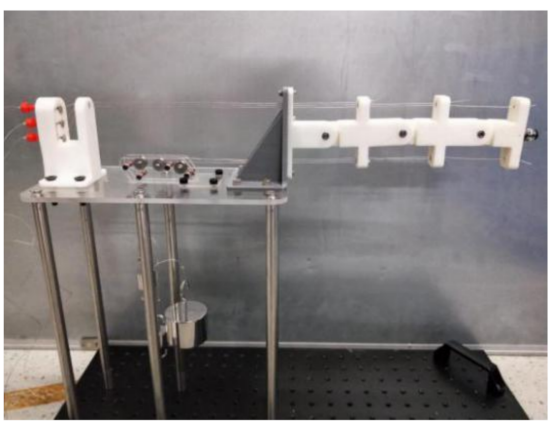

(b)

Figure 12. Manipulators in a singular state. (a) Initial configuration under a singular state; (b) adding $-1 \mathrm{~mm}$ cable length error under a singular state.

In this section, by comparing the simulation and the experimental measurement results, we verified the correctness regarding the influence trend of the cable length error on the tip position. However, the precise change of the tip position caused by the cable length error could not be obtained. This is because only the main influence factor (cable length error) was analyzed in the simulation, and there were other secondary factors which had the characteristics of diversity and randomness during the actual experiment process, such as the experimental system error, mathematical calculation error, measurement error, and so on.

\section{Conclusions}

The CDSM was driven by cables, and the tip positioning accuracy of the manipulator decreased due to the flexibility of the cable. This paper focused on the influence factors that affected the tip positioning accuracy, including the cable length error and cable hole location error.

Firstly, the mappings among the joint angles, the end pose, and the cable lengths were analyzed and a kinematic model was derived in this paper. Next, the error analysis method was illustrated. According to the proposed error analysis method, we respectively studied the influence of the cable length error, cable hole location error, and combined error of them on the tip positioning accuracy by taking a planar CDSM with 3 joints and 6 cables as the experimental model. The results showed that the cable length and cable hole location errors indeed affected the tip positioning accuracy, and especially 
at some special points in the workspace, this could cause an approximate $30 \mathrm{~mm}$ deviation in position. The effect of the cable hole location error was smaller than that of the cable length error; generally the position deviation caused by the cable length error was 2 to 50 times as large as the cable hole location error. In order to verify the theoretical value obtained through simulation, an experimental prototype was established. Through comparing the simulation and the experimental measurement results, we verified the correctness of the influence trend of the cable length error on the tip position.

Therefore, the tip positioning accuracy of the end-effector could be improved by increasing cable control accuracy and making the cable hole size close to the cable diameter. For one thing, if the cable hole size was much larger than the cable diameter, it would increase the cable location error in the experiment. Because the center of the hole was considered as the position of cable that passes through the disk in simulation, too large a cable hole would make the cable deviate from the center during the actual experiment. For another, if the cable hole size was very close to the cable diameter, it could be difficult for the cable to pass through the hole. If the cable was stuck too tight, the friction increased and it was difficult for the cable to slide. Results indicate that the tip positioning accuracy was affected greatly by the error in some special points in the workspace of the manipulator. If we can avoid these special points in trajectory planning, the tip positioning accuracy will be significantly improved.

Author Contributions: Conceptualization, H.Y.; methodology, W.Z.; software, C.L.; validation, W.Z.; formal analysis, W.Z.; investigation, H.Y.; resources, H.Y.; data curation, C.L.; writing-original draft preparation, W.Z. and C.L.; writing-review and editing, H.Y.; visualization, C.L.; supervision, H.Y.; project administration, H.Y.; funding acquisition, H.Y. All authors have read and agreed to the published version of the manuscript.

Funding: This research was funded by the National Natural Science Foundation of China (Grant No. 61803125), the National Natural Science Foundation of Guangdong Province China (Grant No. 2018A030313247), and the Basic Research Program of Shenzhen (Grant No. JCYJ20190806144416980 and JCYJ20180507183644237).

Conflicts of Interest: The authors declare no conflict of interest.

\section{References}

1. Yim, M.; Roufas, K.; Duff, D.; Zhang, Y.; Eldershaw, C.; Homans, S. Modular reconfigurable robots in space applications. Auton. Robots 2003, 14, 225-237. [CrossRef]

2. Transeth, A.A.; Pettersen, K.Y. Developments in snake robot modeling and locomotion. In Proceedings of the 2006 9th International Conference on Control, Automation, Robotics and Vision, Singapore, 5-8 December 2006; pp. 1-8.

3. Morris, M.; Shoham, M. Applications and theoretical issues of cable-driven robots. In Proceedings of the Florida Conference on Recent Advances in Robotics, Boca Raton, FL, USA, 21-22 May 2009; pp. 1-29.

4. Chirikjian, G.S.; Burdick, J.W. The kinematics of hyper-redundant robot locomotion. IEEE Trans. Robot. 1995, 11, 781-793. [CrossRef]

5. Xu, W.; Liu, T.; Li, Y. Kinematics, dynamics, and control of a cable-driven hyper-redundant manipulator. IEEE ASME Trans. Mechatron. 2018, 23, 1693-1704. [CrossRef]

6. Tang, L.; Huang, J.; Zhu, L.M.; Zhu, X.; Gu, G. Path tracking of a cable-driven snake robot with a two-level motion planning method. IEEE ASME Trans. Mechatron. 2019, 24, 935-946. [CrossRef]

7. Choset, H.M.; Luntz, J.E.; Shammas, E.; Rached, T.; Hull, D.; Dent, C.C. Design and motion planning for serpentine robots. In Proceedings of the Smart Structures and Materials 2000: Smart Electronics and MEMS, Newport Beach, CA, USA, 21-24 September 1999; pp. 148-155.

8. Tang, L.; Zhu, L.M.; Zhu, X.; Gu, G. A serpentine curve based motion planning method for cable-driven snake robots. In Proceedings of the 2018 25th International Conference on Mechatronics and Machine Vision in Practice (M2VIP), Stuttgart, Germany, 20-22 November 2018; pp. 1-6.

9. Racioppo, P.; Ben-Tzvi, P. Modeling and control of a cable driven modular snake robot. In Proceedings of the 2017 IEEE Conference on Control Technology and Applications (CCTA), Mauna Lani, HI, USA, 27-30 August 2017; pp. 468-473.

10. Qi, F.; Ju, F.; Bai, D.; Wang, Y.; Chen, B. Kinematic analysis and navigation method of a cable-driven continuum robot used for minimally invasive surgery. Int. J. Med. Robot. 2019, 15, e2007. [CrossRef] [PubMed] 
11. Yuan, H.; Zhou, L.; Xu, W. A comprehensive static model of cable-driven multi-section continuum robots considering friction effect. Mech. Mach. Theory 2019, 135, 130-149. [CrossRef]

12. Yuan, H.; Li, Z. Workspace analysis of cable-driven continuum manipulators based on static model. Robot Comput. Integr. Manuf. 2018, 49, 240-252. [CrossRef]

13. Rone, W.S.; Ben-Tzvi, P. Continuum robot dynamics utilizing the principle of virtual power. IEEE Trans. Robot. 2013, 30, 275-287. [CrossRef]

14. Li, Z.; Du, R.; Lei, M.C.; Yuan, S.M. Design and analysis of a biomimetic wire-driven robot arm. In Proceedings of the ASME International Mechanical Engineering Congress and Exposition, Denver, CO, USA, 1-17 November 2011; pp. 191-198.

15. Wu, H.; Yin, M.; Xu, Z.; Zhao, Z.; Han, W. Transmission Characteristics Analysis and Compensation Control of Double Tendon-sheath Driven Manipulator. Sensors 2020, 20, 1301. [CrossRef] [PubMed]

16. Qian, S.; Bao, K.; Zi, B.; Wang, N. Kinematic calibration of a cable-driven parallel robot for 3D printing. Sensors 2018, 18, 2898. [CrossRef] [PubMed]

17. Zi, B.; Yin, G.; Zhang, D. Design and optimization of a hybrid-driven waist rehabilitation robot. Sensors 2016, 16, 2121. [CrossRef] [PubMed]

18. Fortin-Côté, A.; Cardou, P.; Campeau-Lecours, A. Improving cable driven parallel robot accuracy through angular position sensors. In Proceedings of the 2016 IEEE/RSJ International Conference on Intelligent Robots and Systems (IROS), Daejeon, Korea, 9-14 October 2016; pp. 4350-4355.

19. Lv, W.; Tao, L.; Ji, Z. Sliding mode control of cable-driven redundancy parallel robot with 6 DOF based on cable-length sensor feedback. Math. Probl. Eng. 2017. [CrossRef]

20. Dit Sandretto, J.A.; Daney, D.; Gouttefarde, M. Calibration of a fully-constrained parallel cable-driven robot. In Romansy 19-Robot Design, Dynamics and Control; Padois, V., Bidaud, P., Khatib, O., Eds.; CISM International Centre for Mechanical Sciences, Springer: Vienna, Austria, 2013; Volume 544, pp. 77-84. [CrossRef]

21. Sareh, S.; Noh, Y.; Li, M.; Ranzani, T.; Liu, H.; Althoefer, K. Macrobend optical sensing for pose measurement in soft robot arms. Smart Mater. Struct. 2015, 24, 125024. [CrossRef]

22. Dallej, T.; Gouttefarde, M.; Andreff, N.; Michelin, M.; Martinet, P. Towards vision-based control of cable-driven parallel robots. In Proceedings of the 2011 IEEE/RSJ International Conference on Intelligent Robots and Systems, San Francisco, CA, USA, 25-30 September 2011; pp. 2855-2860. 